\title{
Effect of carbon hybridization in C-F bond as an electron donor in triel bonds
}

Cite as: J. Chem. Phys. 153, 074304 (2020); https://doi.org/10.1063/5.0018950

Submitted: 19 June 2020 . Accepted: 29 July 2020 . Published Online: 17 August 2020

Qingqing Yang, Zongqing Chi, Qingzhong Li (D), and Steve Scheiner (D)

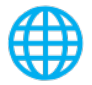

\section{ARTICLES YOU MAY BE INTERESTED IN}

Electronic structure software

The Journal of Chemical Physics 153, 070401 (2020); https://doi.org/10.1063/5.0023185

Bond dissociation energies of transition metal oxides: $\mathrm{CrO}, \mathrm{MoO}, \mathrm{RuO}$, and $\mathrm{RhO}$

The Journal of Chemical Physics 153, 074303 (2020); https://doi.org/10.1063/5.0021052

$\mathrm{H}_{2} \mathrm{O}-\mathrm{CO}$ and $\mathrm{D}_{2} \mathrm{O}-\mathrm{CO}$ complexes: Intra- and intermolecular rovibrational states from fulldimensional and fully coupled quantum calculations

The Journal of Chemical Physics 153, 074107 (2020); https://doi.org/10.1063/5.0020566

\section{Lock-in Amplifiers up to $600 \mathrm{MHz}$}
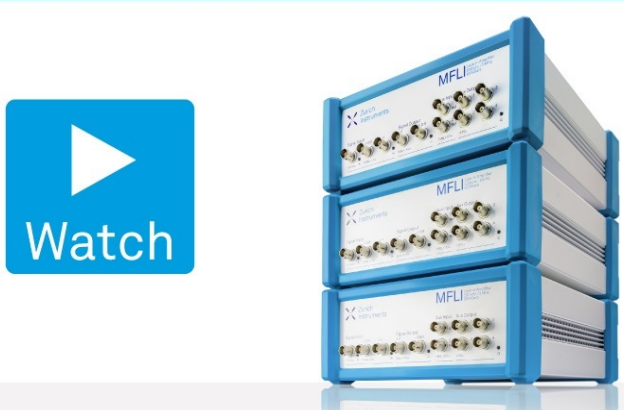

J. Chem. Phys. 153, 074304 (2020); https://doi.org/10.1063/5.0018950 


\title{
Effect of carbon hybridization in $\mathrm{C}-\mathrm{F}$ bond as an electron donor in triel bonds
}

\author{
Cite as: J. Chem. Phys. 153, 074304 (2020); doi: 10.1063/5.0018950 \\ Submitted: 19 June 2020 - Accepted: 29 July 2020 • \\ Published Online: 17 August 2020
}

Qingqing Yang, ${ }^{,}$Zongqing Chi, ${ }^{,}$Qingzhong $\mathrm{Li}^{1,{ }^{1, a)}}$ (D) and Steve Scheiner ${ }^{2, a)}$ (D)

\begin{abstract}
AFFILIATIONS
${ }^{1}$ The Laboratory of Theoretical and Computational Chemistry, School of Chemistry and Chemical Engineering, Yantai University, Yantai 264005, People's Republic of China

${ }^{2}$ Department of Chemistry and Biochemistry, Utah State University, Logan, Utah 84322-0300, USA
\end{abstract}

a) Authors to whom correspondence should be addressed: liqingzhong1990@sina.com and steve.scheiner@usu.edu

\begin{abstract}
The ability of the $\mathrm{F}$ atom of $\mathrm{HC} \equiv \mathrm{CF}, \mathrm{H}_{2} \mathrm{C}=\mathrm{CHF}$ and $\mathrm{H}_{3} \mathrm{CCH}_{2} \mathrm{~F}$ to serve as an electron donor to the triel ( $\mathrm{Tr}$ ) atom of $\mathrm{TrR}$ in the context of a triel bond is assessed by ab initio calculations. The triel bond formed by $\mathrm{C}_{\mathrm{sp} 3}-\mathrm{F}$ is strongest, as high as $30 \mathrm{kcal} / \mathrm{mol}$, followed by $\mathrm{C}_{\mathrm{sp} 2}-\mathrm{F}$, and then by $\mathrm{C}_{\mathrm{sp}}-\mathrm{F}$ whose triel bonds can be as small as $1 \mathrm{kcal} / \mathrm{mol}$. The noncovalent bond strength diminishes in the order $\mathrm{Tr}=\mathrm{Al}>\mathrm{Ga}>\mathrm{B}$, consistent with the intensity of the $\pi$-hole above the $\mathrm{Tr}$ atom in the monomer. The triel bond strength of the $\mathrm{Al}$ and $\mathrm{Ga}$ complexes increases along with the electronegativity of the $\mathrm{R}$ substituent but is largest for $\mathrm{R}=\mathrm{H}$ when $\mathrm{Tr}=\mathrm{B}$. Electrostatics play the largest role in the stronger triel bonds, but dispersion makes an outsized contribution for the weakest such bonds.
\end{abstract}

Published under license by AIP Publishing. https://doi.org/10.1063/5.0018950

\section{INTRODUCTION}

Noncovalent interactions play an important role in many fields such as crystalline materials, ${ }^{1-3}$ chemical reactions, ${ }^{4-6}$ molecular recognition, ${ }^{7-9}$ and biological systems. ${ }^{10-12}$ Now thousands of studies involving noncovalent interactions are reported each year. One of the goals is to explore which species can serve as electron donors in such interactions, and how effective they might be. The most common electron donors are the lone pairs of atoms, either on halogen atoms or on oxygen, nitrogen, etc. The electron donor capability of halogens has attracted a good deal of attention. ${ }^{13-17}$ These halogen species include carbon-bound and terminal metalbound halogens and halide ions. Anion recognition, particularly for $\mathrm{F}^{-}$and $\mathrm{Cl}^{-}$, has been realized by means of hydrogen bond $(\mathrm{HB})$ and/or halogen bond (XB), ${ }^{7,8}$ utilizing the anion as a particularly effective electron donor. Halide ions form a stronger noncovalent interaction with smaller anions: $\mathrm{F}^{-}>\mathrm{Cl}^{-}>\mathrm{Br}^{-}>\mathrm{I}^{-}$. Halide ligands $(\mathrm{M}-\mathrm{X})$ have also been demonstrated to be excellent electron donors in $\mathrm{HBs}$ and XBs. Interest in noncovalent interactions involving halide ligands centers around molecular building blocks, constructing functional materials with magnetic, thermochromic, and photoelectric properties. ${ }^{18}$ Organic halogens bonded to carbon are also a focus since halocarbons are extensively present in organic molecules. It is usually accepted that halocarbons are much poorer electron donors in HBs than halide ions and halide ligands.

Due to its electron-deficient nature, boron trihydride $\left(\mathrm{BH}_{3}\right)$ and boron trihalides $\left(\mathrm{BX}_{3}\right)$ are often used to bind with small molecules such as $\mathrm{HCN}$ and $\mathrm{NH}_{3}$, forming a partially covalent Lewis acid-base complex suggested by Leopold and co-workers. ${ }^{19-21}$ Such complexes have attracted interest since they have been postulated early on as transition states in $\mathrm{S}_{\mathrm{N}} 2$ reactions such as the reactions of borine carbonyl $\left(\mathrm{BH}_{3}-\mathrm{CO}\right)$ and trimethylamine ${ }^{22,23}$ as well as the borate-fluorine bond cleavage reaction by electronrich late-transition metal complexes. ${ }^{24}$ In such a $\mathrm{S}_{\mathrm{N}} 2$ reaction, a pentacoordinate boron compound is formed, and this type of compound has been isolated. ${ }^{25}$ According to the molecular electrostatic potential (MEP) analysis, the boron atom in the tricoordinate boron compound has a positive MEP region, often termed a $\pi$-hole, which lies above the molecular plane. ${ }^{26}$ Besides boron, other atoms in the same group also participate in a similar interaction, frequently called a triel bond $(\operatorname{TrB})$, which occurs between the $\pi$-hole on the triel atom and an electron donor. $^{2}$ 
The TrB displays some unexpected properties. The $\pi$-hole on the $\mathrm{BF}_{3}$ molecule is larger than that on the $\mathrm{BH}_{3}$ molecule, but yet a stronger triel bond is found for the latter molecule. ${ }^{28} \mathrm{TrB}$ can combine with $\mathrm{HB}, \mathrm{XB}$, or pnicogen bond (ZB), ${ }^{20,29,30}$ displaying cooperativity. In $\mathrm{BF}_{3} \cdots \mathrm{NCH} \cdots \mathrm{NCH}, \mathrm{BF}_{3} \cdots \mathrm{NCX} \cdots \mathrm{NCH}(\mathrm{X}=$ halogen), and $\mathrm{BF}_{3} \cdots \mathrm{NCZH}_{2} \cdots \mathrm{NH}_{3}(\mathrm{Z}=\mathrm{P}, \mathrm{As}, \mathrm{Sb})$, the $\mathrm{TrB}$ shows a positive cooperativity with the $\mathrm{HB}, \mathrm{XB}$, or $\mathrm{ZB}$, and both interactions enhance one another. ${ }^{20,29,30}$ However, the intermolecular distance in the stronger $\operatorname{TrB}$ is shortened by more than the other interaction, ${ }^{20,29,30}$ opposite to the usual conclusion that the larger contraction takes place for the weaker interaction. ${ }^{31}$ These unexpected variations are to a great extent ascribed to prominent distortion of the tricoordinate triel molecule in the formation of a $\operatorname{TrB}$, which is changed from a planar structure in the isolated molecule into a pyramidal geometry in the complex. ${ }^{32}$ This larger deformation stresses the importance of polarization for the formation of a $\operatorname{TrB}{ }^{3}$ Even so, the $\operatorname{TrB}$ is steered by the same mechanism as $\mathrm{HB}$ and $\mathrm{XB}$ in which charge transfers from the Lewis base to the Lewis acid unit. $^{34}$

There has been some research in the past that probed the possibility of various $\operatorname{TrB}$ electron donors, not only conventional lone pairs, anions, ${ }^{35}$ but also $\pi$-electron systems ${ }^{36-38}$ and even more unconventional electron donors such as metal hydrides, ${ }^{39,40}$ radicals, ${ }^{41}$ and carbenes. ${ }^{42}$ A TrB can be very strong, with interaction energies reaching more than $100 \mathrm{kcal} / \mathrm{mol}$. On the other end of the spectrum, the dihydrogen bond between phenol and diethylmethylsilane is very weak $(3 \mathrm{kcal} / \mathrm{mol}),{ }^{43}$ indicating that the $\mathrm{Si}-\mathrm{H}$ bond is a weak electron donor. Nonetheless, this weak donor can still manage to form a strong $\operatorname{TrB}$ with $\mathrm{BH}_{3}(40 \mathrm{kcal} / \mathrm{mol}){ }^{39}$ In the study of TrBs, the usual electron donors are oxygen-containing and nitrogen-containing molecules. ${ }^{44}$ Very recently, for example, our group ${ }^{45}$ compared the $\operatorname{TrB}$ with different chalcogen electron donors, and it was found that the $\operatorname{TrB}$ is stronger in the $\mathrm{O}>\mathrm{S} \approx \mathrm{Se}$ order.

Besides these common donors, $\operatorname{TrBs}$ with halogens as the donor have been subject to some examination. The complexes of $\mathrm{BH}(\mathrm{CO})_{2} / \mathrm{BH}\left(\mathrm{N}_{2}\right)_{2}$ with $\mathrm{XF}_{3} / \mathrm{XF}_{5}(\mathrm{X}=\mathrm{Cl}, \mathrm{Br}$, and $\mathrm{I})$ are bonded by a combination of a $\mathrm{XB}$ and $\mathrm{a} \operatorname{TrB}$, where the $\mathrm{XB}$ makes a larger contribution than the $\operatorname{TrB}{ }^{46}$ This $\operatorname{TrB}$ is formed between the $\sigma$-hole on the $\mathrm{B}$ atom along the $\mathrm{B}-\mathrm{H}$ bond, and the negatively charged $\mathrm{F}$ atom. $\mathrm{BH}_{2} \mathrm{X}(\mathrm{X}=\mathrm{F}, \mathrm{Cl}, \mathrm{Br}$, and $\mathrm{I})$ can form a dimer through hydrogen, halogen, or triel bonding interactions, of which the most stable dimer is primarily stabilized by triel bonding. Interestingly, the $\mathrm{B} \cdots \mathrm{X}$ triel-bond is stronger for the heavier halogen atom, opposite to the negative electrostatic potential on the $\mathrm{X}$ atom. ${ }^{47}$ In the triel-bonded complexes using a halogen anion as the electron donor, the interaction becomes stronger for the lighter halogen anion. ${ }^{3}$ Moreover, the triel-boned complexes using two triel atoms bonded to an anion are so very stable that they can be found in some crystal structures. ${ }^{44}$

However, none of the above studies of TrBs considered carbonbound halogens, so the concept of a halogen atom acting as an electron donor in a triel bond represents untrodden ground. However, such a role for organic $\mathrm{F}$ is widely known, not only in the context of crystal engineering but also in the design of functional materials. ${ }^{48}$ Although Dunitz and Taylor concluded that organic fluorine is not a good electron donor in $\mathrm{HBs},{ }^{49}$ the triel bond is quite different in some respects so it is important to assess $F$ in this context. The research described below represents a first attempt to rectify this deficiency. As a Lewis acid, a set of $\operatorname{TrR}_{3}$ molecules are considered. As a central Tr atom, B, Al, and Ga are considered so as to examine the dependence on the size of the triel atom. Substituents $\mathrm{R}$ include $\mathrm{H}, \mathrm{F}, \mathrm{Cl}$, and $\mathrm{Br}$, which thus offer a wide range of electronwithdrawing capacity. The electron donating $\mathrm{F}$ atom is attached to a $\mathrm{C}$ atom, which takes on one of three hybridizations. This $\mathrm{C}$ is $\mathrm{sp}^{3}$-hybridized in $\mathrm{CH}_{3} \mathrm{CH}_{2} \mathrm{~F}$ but takes on $\mathrm{sp}^{2}$-hybridization in $\mathrm{CH}_{2}=\mathrm{CHF}$, while $\mathrm{CH}_{3} \mathrm{CH}_{2} \mathrm{~F}$ presents sp-hybridization. All combinations of these systems are considered, making for a total of 36 different heterodimers. The research seeks to first determine whether or not a $\mathrm{C}-\mathrm{F}$ bond can participate in a triel bond. The work then proceeds to assess the effects of the size of the triel atom, the electronegativity of the three substituents, and the hybridization of the $\mathrm{C}$ atom to which the $\mathrm{F}$ atom is bound. The calculations finally address the fundamental aspects of these triel bonds, what are their most basic physical origins.

\section{THEORETICAL METHODS}

Gaussian09 software was utilized to perform all calculations of complexes and monomers. ${ }^{50}$ All structures were optimized at the MP2/aug-cc-pVTZ level. To insure a minimum, frequency calculations were then carried out for these species at the same level. The interaction energy $\mathrm{E}^{\text {int }}$ compared the energy of the complex with the sum of monomers within the geometry adopted within the dimer. The binding energy $E_{b}$ takes as its reference the monomers in their fully optimized structures. Deformation energy is defined as the difference between the two, the energy required for the pair of monomers to adjust their geometry for complexation. The Boys and Bernardi counterpoise method ${ }^{51}$ was used to correct the basis set superposition error (BSSE) for both $E^{\text {int }}$ and $\mathrm{E}^{\mathrm{b}}$.

The molecular electrostatic potentials (MEPs) of the monomers on the 0.001 a.u. isodensity surface were evaluated at the MP2/augcc-pVTZ level by means of the Wave Function Analysis-Surface Analysis Suite program. ${ }^{52}$ AIM2000 software ${ }^{53}$ was applied to obtain the electron density, Laplacian, and energy density at the relevant bond critical points (BCPs). Using the NBO3.0 package ${ }^{54}$ in the Gaussian09 software, the natural bond orbital analysis was performed at the HF/aug-cc-pVTZ level to obtain orbital interaction and charge transfer data. By means of the LMOEDA (localized molecular orbital energy decomposition analysis) method $^{55}$ in the GAMESS program, ${ }^{56}$ the total interaction energy was decomposed at the MP2/aug-cc-pVTZ level, and five kinds of energy with physical significance were obtained: electrostatic energy $\left(E^{\text {ele }}\right)$, exchange energy $\left(E^{e x}\right)$, repulsion energy $\left(E^{\text {rep }}\right)$, polarization energy $\left(E^{\mathrm{pol}}\right)$, and dispersion energy $\left(\mathrm{E}^{\mathrm{disp}}\right)$.

\section{RESULTS}

\section{sp alkynes}

All of the complexes of $\mathrm{HC} \equiv \mathrm{CF}$ with $\mathrm{TrR}_{3}$ take on a geometry like that pictured in Fig. 1. The F atom of HCCF lies close to the $\mathrm{C}_{3}$ axis of $\mathrm{TrR}_{3}$ at a distance $\mathrm{R}$ from the $\mathrm{Tr}$ atom. The HCCF molecule is turned by an angle $a$ so that one of the $\mathrm{F}$ lone pairs can 

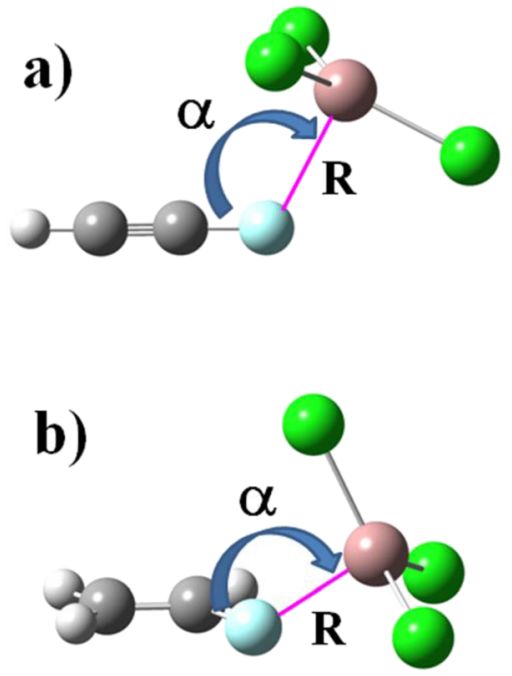

FIG. 1. Geometries of the complexes of (a) HCCF, (b) $\mathrm{H}_{2} \mathrm{C}=\mathrm{CHF}$, and (c) $\mathrm{H}_{3} \mathrm{C}-\mathrm{CH}_{2} \mathrm{~F}$ with $\mathrm{TrR}_{3}$.

optimally approach the $\operatorname{Tr}$ atom. Note that this orientation is also consistent with the minima on the HCCF MEP. The distance R and angle $\alpha$ of the various complexes are all listed in Table I along with energetic properties. The $\alpha$ angle varies between $102^{\circ}$ and $124^{\circ}$, typically largest for $\mathrm{TrF}_{3}$ in any subset of a particular $\mathrm{Tr}$ atom. This may be due, in part, to Coulombic repulsions between the $\mathrm{F}$ atoms on the $\mathrm{TrF}_{3}$ and the negative regions on the HCCF unit. It is also the $\mathrm{TrF}_{3}$ molecule that has the shortest intermolecular $\mathrm{R}$ distance, with the exception of $\operatorname{Tr}=\mathrm{B}$, where it is shorter for $\operatorname{TrH}_{3}$. With regard to energetics, the interaction energies range between $-0.9 \mathrm{kcal} / \mathrm{mol}$ and $-5.5 \mathrm{kcal} / \mathrm{mol}$. These quantities increase in the order $\mathrm{B}<\mathrm{Ga}$ $<\mathrm{Al}$ and for any given $\mathrm{Tr}$ atom $\mathrm{R}=\mathrm{H}<\mathrm{Br}<\mathrm{Cl}<\mathrm{F}$, i.e., increasing electronegativity.

Table II displays a quantitative assessment of the charge shifts in the complexes. CT refers to the total amount of density shifted between molecules from HCCF to $\mathrm{TrR}_{3}$, while $\mathrm{E}^{(2)}$ focuses on one particular inter-orbital transfer, from a lone pair of $\mathrm{F}$ to the unfilled lone pair orbital of $\mathrm{Tr}$, essentially a $p$-orbital. These measures of charge transfer mirror the energetics reasonably well: they are also largest for $\mathrm{Al}$ and smallest for $\mathrm{B}$ and rise along with the electronegativity of $\mathrm{R}$ (with the exception of $\mathrm{Tr}=\mathrm{B}$ for which $\mathrm{H}$ is largest). Other
TABLE I. Interaction energy $E^{\text {int }}$, binding energy $E^{b}$, deformation energy $D E$, all in $\mathrm{kcal} / \mathrm{mol}, \mathrm{Tr} \ldots \mathrm{F}$ intermolecular distance $(\mathrm{R})$, and C-F ...Tr angle $(\alpha)$ in the complexes.

\begin{tabular}{|c|c|c|c|c|c|}
\hline Complexes & $\mathrm{E}^{\mathrm{int}, \mathrm{a}}$ & $E^{b}$ & $\mathrm{DE}$ & $\mathrm{R}(\AA)$ & $\alpha(\operatorname{deg})$ \\
\hline \multicolumn{6}{|l|}{$\mathrm{C}_{\mathrm{sp}}-\mathrm{F}$} \\
\hline $\mathrm{BH}_{3}$ & -1.11 & -1.09 & 0.02 & 2.556 & 113.5 \\
\hline $\mathrm{BF}_{3}$ & -0.94 & -0.92 & 0.02 & 2.711 & 115.5 \\
\hline $\mathrm{BCl}_{3}$ & -1.66 & -1.66 & 0.00 & 2.984 & 103.3 \\
\hline $\mathrm{BBr}_{3}$ & $-1.79(-1.89)$ & -1.79 & 0.00 & 2.982 & 102.2 \\
\hline $\mathrm{AlH}_{3}$ & -2.21 & -1.98 & 0.23 & 2.469 & 119.2 \\
\hline $\mathrm{AlF}_{3}$ & -5.51 & -4.17 & 1.34 & 2.160 & 121.9 \\
\hline $\mathrm{AlCl}_{3}$ & -3.96 & -3.02 & 0.94 & 2.310 & 120.3 \\
\hline $\mathrm{AlBr}_{3}$ & $-3.24(-3.35)$ & -2.57 & 0.67 & 2.393 & 118.7 \\
\hline $\mathrm{GaH}_{3}$ & $-1.23(-1.28)$ & -1.07 & 0.16 & 2.461 & 120.8 \\
\hline $\mathrm{GaF}_{3}$ & $-3.16(-3.26)$ & -2.19 & 0.97 & 2.189 & 123.7 \\
\hline $\mathrm{GaCl}_{3}$ & $-2.31(-2.34)$ & -1.83 & 0.48 & 2.403 & 120.3 \\
\hline $\mathrm{GaBr}_{3}$ & $-2.11(-2.20)$ & -1.85 & 0.26 & 2.527 & 116.9 \\
\hline \multicolumn{6}{|l|}{$\mathrm{C}_{\mathrm{sp} 2}-\mathrm{F}$} \\
\hline $\mathrm{BH}_{3+}$ & -4.22 & -3.32 & 0.90 & 2.130 & 114.3 \\
\hline $\mathrm{BF}_{3}$ & -3.31 & -2.98 & 0.33 & 2.468 & 118.1 \\
\hline $\mathrm{BCl}_{3}$ & -2.78 & -2.70 & 0.08 & 2.799 & 109.5 \\
\hline $\mathrm{BBr}_{3}$ & $-2.47(-2.56)$ & -2.41 & 0.06 & 2.826 & 107.1 \\
\hline $\mathrm{AlH}_{3}$ & -11.09 & -8.79 & 2.30 & 2.113 & 120.5 \\
\hline $\mathrm{AlF}_{3}$ & -21.32 & -15.61 & 5.71 & 1.960 & 123.1 \\
\hline $\mathrm{AlCl}_{3}$ & -19.08 & -13.27 & 5.81 & 1.983 & 121.8 \\
\hline $\mathrm{AlBr}_{3}$ & $-17.35(-17.52)$ & -11.84 & 5.51 & 1.992 & 122.0 \\
\hline $\mathrm{GaH}_{3}$ & $-6.24(-6.12)$ & -4.90 & 1.34 & 2.204 & 121.7 \\
\hline $\mathrm{GaF}_{3}$ & $-15.83(-15.87)$ & -11.64 & 4.19 & 2.034 & 123.7 \\
\hline $\mathrm{GaCl}_{3}$ & $-11.47(-11.36)$ & -8.07 & 3.40 & 2.104 & 121.3 \\
\hline $\mathrm{GaBr}_{3}$ & $-9.84(-9.93)$ & -6.71 & 3.13 & 2.133 & 120.1 \\
\hline \multicolumn{6}{|l|}{$\mathrm{C}_{\mathrm{sp} 3}-\mathrm{F}$} \\
\hline $\mathrm{BH}_{3}$ & -9.95 & -6.10 & 3.85 & 1.856 & 114.8 \\
\hline $\mathrm{BF}_{3}$ & -5.69 & -4.67 & 1.02 & 2.283 & 115.4 \\
\hline $\mathrm{BCl}_{3}$ & -3.73 & -3.51 & 0.22 & 2.662 & 113.0 \\
\hline $\mathrm{BBr}_{3}$ & $-3.35(-3.45)$ & -3.15 & 0.20 & 2.693 & 110.9 \\
\hline $\mathrm{AlH}_{3}$ & -17.15 & -13.81 & 3.34 & 2.026 & 117.9 \\
\hline $\mathrm{AlF}_{3}$ & -29.74 & -22.42 & 7.32 & 1.910 & 121.7 \\
\hline $\mathrm{AlCl}_{3}$ & -27.45 & -20.12 & 7.33 & 1.918 & 121.8 \\
\hline $\mathrm{AlBr}_{3}$ & $-26.00(-26.18)$ & -18.82 & 7.18 & 1.922 & 121.6 \\
\hline $\mathrm{GaH}_{3}$ & $-10.15(-9.98)$ & -8.16 & 1.99 & 2.130 & 116.8 \\
\hline $\mathrm{GaF}_{3}$ & $-23.05(-23.13)$ & -17.60 & 5.45 & 1.987 & 120.4 \\
\hline $\mathrm{GaCl}_{3}$ & $-18.24(-18.09)$ & -13.48 & 4.76 & 2.034 & 120.3 \\
\hline $\mathrm{GaBr}_{3}$ & $-16.33(-16.41)$ & -11.79 & 4.54 & 2.052 & 119.9 \\
\hline
\end{tabular}

${ }^{\mathrm{a}} \mathrm{Data}$ in parentheses refer to interaction energies calculated at the MP2/aug-ccpVTZ(PP) level.

gauges of bond strength arise from AIM analysis of the electron density topology, data for which are listed in Table III. The density $(\rho)$, its Laplacian $\left(\nabla^{2} \rho\right)$, and the energy density $(H)$ all refer to the bond critical point between $\mathrm{F}$ and $\mathrm{Tr}$. Like the charge transfer parameters in Table II, the atoms in molecules (AIM) measures of noncovalent bond strength conform to the same general patterns as do the energetics, with the exception that the Ga quantities exceed the $\mathrm{Al}$ values. 
TABLE II. Charge transfer $(Q, e)$ from F-containing molecule to $\mathrm{TrR}_{3}$ and NBO perturbation energy $\left[E^{(2)}, \mathrm{kcal} / \mathrm{mol}\right]$ for transfer from the $\mathrm{F}$ lone pair to the Tr unfilled lone pair orbital.

\begin{tabular}{|c|c|c|c|c|c|c|}
\hline \multirow[b]{2}{*}{ Complexes } & \multicolumn{2}{|c|}{$\mathrm{C}_{\mathrm{sp}}-\mathrm{F}$} & \multicolumn{2}{|c|}{$\mathrm{C}_{\mathrm{sp} 2}-\mathrm{F}$} & \multicolumn{2}{|c|}{$\mathrm{C}_{\mathrm{sp} 3}-\mathrm{F}$} \\
\hline & Q & $\mathrm{E}^{(2)}$ & Q & $E^{(2)}$ & Q & $E^{(2)}$ \\
\hline $\mathrm{BH}_{3}$ & 0.0140 & 8.23 & 0.0537 & 38.09 & 0.1177 & \\
\hline $\mathrm{BF}_{3}$ & 0.0040 & 1.56 & 0.0106 & 6.36 & 0.0230 & 15.17 \\
\hline $\mathrm{BCl}_{3}$ & 0.0044 & 2.84 & 0.0091 & 6.16 & 0.0143 & 11.09 \\
\hline $\mathrm{BBr}_{3}$ & 0.0058 & 4.28 & 0.0104 & 8.96 & 0.0160 & 13.83 \\
\hline $\mathrm{AlH}_{3}$ & 0.0300 & 19.93 & 0.0722 & 57.52 & 0.0892 & 71.51 \\
\hline $\mathrm{AlF}_{3}$ & 0.0435 & 32.19 & 0.0778 & 67.08 & 0.0918 & 80.33 \\
\hline $\mathrm{AlCl}_{3}$ & 0.0421 & 33.83 & 0.0909 & 80.10 & 0.1050 & \\
\hline $\mathrm{AlBr}_{3}$ & 0.0384 & 31.77 & 0.0894 & 78.39 & 0.1029 & 89.05 \\
\hline $\mathrm{GaH}_{3}$ & 0.0294 & 20.98 & 0.0618 & 48.35 & 0.0779 & 60.93 \\
\hline $\mathrm{GaF}_{3}$ & 0.0431 & 29.59 & 0.0729 & 55.25 & 0.0880 & 67.68 \\
\hline $\mathrm{GaCl}_{3}$ & 0.0358 & 27.48 & 0.0793 & 65.64 & 0.0948 & 77.85 \\
\hline $\mathrm{GaBr}_{3}$ & 0.0292 & 23.52 & 0.0747 & 63.71 & 0.0911 & 76.14 \\
\hline
\end{tabular}

The division of the total interaction energy into its constituent parts is displayed in Table IV. The attractive part of the exchange energy is the largest component, with the other terms somewhat lower. The dispersion energy exceeds the other two for $\mathrm{BR}_{3}$, but the reverse is true for the other two $\operatorname{Tr}$ atoms. $\mathrm{E}^{\text {ele }}$ and $\mathrm{E}^{\mathrm{pol}}$ are generally comparable to one another although the former tends to be larger than the latter.

One can consider the disposition of the molecular electrostatic potential (MEP) surrounding each monomer as a means of helping understand the geometry adopted by a given dimer. The MEP of $\mathrm{HC} \equiv \mathrm{CF}$ in Fig. 2(a) does not have an extreme negative region near the $\mathrm{F}$ atom, which would have been blue in this diagram. The most negative region is a ring around the $\mathrm{F}$ atom, with a $\mathrm{V}_{\mathrm{s} \text {,min }}$ of only -0.0064 a.u. Its position off of the HCCF axis helps to explain the deviation of the $\alpha$ angle from $180^{\circ}$. The small value of $\mathrm{V}_{s, \min }$ is consistent with the relatively small electrostatic energy, especially when compared to the other complexes below.

Each $\operatorname{TrR}_{3}$ molecule contains a positive region, or $\pi$-hole, directly above and below the $\mathrm{Tr}$ atom. The value of the maximum is reported in Table $\mathrm{V}$ and shows some clear trends. For any particular substituent $\mathrm{R}$, the $\pi$-hole above $\mathrm{Al}$ is the most intense, followed by $\mathrm{Ga}$ and then $\mathrm{B}$. This order comports with the Tr electronegativity (B: 2.0, Al: 1.6, Ga: 1.8). $\mathrm{V}_{\mathrm{s}, \max }$ is consistently largest for $\mathrm{R}=\mathrm{F}$, followed by $\mathrm{Cl}$ and then $\mathrm{Br}$ with the latter two being much smaller than $\mathrm{F}$. The placement of $\mathrm{H}$ in this hierarchy is somewhat variable and depends upon Tr. This pattern is not entirely consistent with the electrostatic energies in Table IV. For example, $\mathrm{TrF}_{3}$ does not have the largest $\mathrm{E}^{\text {ele }}$ for $\mathrm{B}$ and $\mathrm{Al}$.

\section{$\mathrm{sp}^{2}$ alkenes}

When combined with $\mathrm{H}_{2} \mathrm{C}=\mathrm{CHF}$, the $\mathrm{TBr}_{3}$ unit situates itself above the alkene's molecular plane, as indicated by a typical such structure in Fig. 1(b). The $\mathrm{R}(\mathrm{Tr} \cdots \mathrm{F})$ distances and $a$ angles are
TABLE III. Electron density $(\rho)$, its Laplacian $\left(\nabla^{2} \rho\right)$, and energy density $(H)$ at the intermolecular F...Tr BCP, all in a.u.

\begin{tabular}{|c|c|c|c|}
\hline Complexes & $\rho$ & $\nabla^{2} \rho$ & $\mathrm{H}$ \\
\hline \multicolumn{4}{|l|}{$\mathrm{C}_{\mathrm{sp}}-\mathrm{F}$} \\
\hline $\mathrm{BH}_{3}$ & 0.0091 & 0.0424 & 0.0015 \\
\hline $\mathrm{BF}_{3}$ & 0.0064 & 0.0319 & 0.0016 \\
\hline $\mathrm{BCl}_{3}$ & 0.0053 & 0.0224 & 0.0010 \\
\hline $\mathrm{BBr}_{3}$ & 0.0057 & 0.0232 & 0.0010 \\
\hline $\mathrm{AlH}_{3}$ & 0.0106 & 0.0470 & 0.0011 \\
\hline $\mathrm{AlF}_{3}$ & 0.0194 & 0.1582 & 0.0078 \\
\hline $\mathrm{AlCl}_{3}$ & 0.0148 & 0.0853 & 0.0029 \\
\hline $\mathrm{AlBr}_{3}$ & 0.0131 & 0.0614 & 0.0014 \\
\hline $\mathrm{GaH}_{3}$ & 0.0169 & 0.0947 & 0.0032 \\
\hline $\mathrm{GaF}_{3}$ & 0.0332 & 0.2139 & 0.0034 \\
\hline $\mathrm{GaCl}_{3}$ & 0.0200 & 0.1092 & 0.0031 \\
\hline $\mathrm{GaBr}_{3}$ & 0.0155 & 0.0757 & 0.0024 \\
\hline \multicolumn{4}{|l|}{$\mathrm{C}_{\mathrm{sp} 2}-\mathrm{F}$} \\
\hline $\mathrm{BH}_{3}$ & 0.0226 & 0.0886 & -0.0001 \\
\hline $\mathrm{BF}_{3}$ & 0.0116 & 0.0520 & 0.0019 \\
\hline $\mathrm{BCl}_{3}$ & 0.0076 & 0.0304 & 0.0012 \\
\hline $\mathrm{BBr}_{3}$ & 0.0078 & 0.0305 & 0.0011 \\
\hline $\mathrm{AlH}_{3}$ & 0.0249 & 0.1883 & 0.0077 \\
\hline $\mathrm{AlF}_{3}$ & 0.0378 & 0.3468 & 0.0142 \\
\hline $\mathrm{AlCl}_{3}$ & 0.0367 & 0.3126 & 0.0119 \\
\hline $\mathrm{AlBr}_{3}$ & 0.0362 & 0.3051 & 0.0115 \\
\hline $\mathrm{GaH}_{3}$ & 0.0337 & 0.2083 & 0.0028 \\
\hline $\mathrm{GaF}_{3}$ & 0.0540 & 0.3622 & -0.0001 \\
\hline $\mathrm{GaCl}_{3}$ & 0.0453 & 0.2820 & 0.0006 \\
\hline $\mathrm{GaBr}_{3}$ & 0.0423 & 0.2577 & 0.0010 \\
\hline \multicolumn{4}{|l|}{$\mathrm{C}_{\mathrm{sp} 3}-\mathrm{F}$} \\
\hline $\mathrm{BH}_{3}$ & 0.0401 & 0.1136 & -0.0120 \\
\hline $\mathrm{BF}_{3}$ & 0.0172 & 0.0682 & 0.0008 \\
\hline $\mathrm{BCl}_{3}$ & 0.0098 & 0.0392 & 0.0014 \\
\hline $\mathrm{BBr}_{3}$ & 0.0099 & 0.0378 & 0.0013 \\
\hline $\mathrm{AlH}_{3}$ & 0.0324 & 0.2670 & 0.0106 \\
\hline $\mathrm{AlF}_{3}$ & 0.0455 & 0.4209 & 0.0150 \\
\hline $\mathrm{AlCl}_{3}$ & 0.0453 & 0.3993 & 0.0136 \\
\hline $\mathrm{AlBr}_{3}$ & 0.0452 & 0.4015 & 0.0135 \\
\hline $\mathrm{GaH}_{3}$ & 0.0420 & 0.2651 & 0.0014 \\
\hline $\mathrm{GaF}_{3}$ & 0.0631 & 0.4239 & -0.0034 \\
\hline $\mathrm{GaCl}_{3}$ & 0.0559 & 0.3574 & -0.0018 \\
\hline $\mathrm{GaBr}_{3}$ & 0.0535 & 0.3384 & -0.0010 \\
\hline
\end{tabular}

displayed in the second section of Table I where it may be seen that the intermolecular distances are much shorter than for the HCCF sp-hybridized structures in the first section. These contractions vary from $0.15 \AA$ to as much as $0.43 \AA$, while the $\alpha(\mathrm{C}-\mathrm{F} \cdots \mathrm{Tr})$ angles change by only a few degrees. Along with the closer contact in the $\mathrm{sp}^{2}$ cases, there is a very substantial rise in the interaction energies. The smallest such increments of $0.7 \mathrm{kcal} / \mathrm{mol}-$ $3.1 \mathrm{kcal} / \mathrm{mol}$ arise in the $\mathrm{BR}_{3}$ complexes, but even here, the percentage increases are impressive, from $38 \%$ to $280 \%$. The interaction energies for $\mathrm{Al}$ and $\mathrm{Ga}$ also increase substantially, by a factor 
TABLE IV. Electrostatic ( $\left.E^{\text {ele }}\right)$, exchange $\left(E^{\mathrm{ex}}\right)$, repulsion $\left(E^{\text {rep }}\right)$, polarization $\left(E^{\mathrm{pol}}\right)$, and dispersion ( $E^{\text {disp }}$ ) energies in $\mathrm{TrR}_{3} \cdots \mathrm{H}_{2} \mathrm{X}$. All in $\mathrm{kcal} / \mathrm{mol}$.

\begin{tabular}{|c|c|c|c|c|c|}
\hline Complexes & $\mathrm{E}^{\text {ele }}$ & $\mathrm{E}^{\mathrm{ex}}$ & $\mathrm{E}^{\text {rep }}$ & $\mathrm{E}^{\mathrm{pol}}$ & $\mathrm{E}^{\text {disp }}$ \\
\hline \multicolumn{6}{|l|}{$\mathrm{C}_{\mathrm{sp}}-\mathrm{F}$} \\
\hline $\mathrm{BH}_{3}$ & -1.33 & -4.20 & 7.34 & -0.75 & -2.19 \\
\hline $\mathrm{BF}_{3}$ & -0.88 & -2.30 & 4.16 & -0.56 & -1.39 \\
\hline $\mathrm{BCl}_{3}$ & -1.02 & -4.80 & 8.12 & -0.37 & -3.63 \\
\hline $\mathrm{BBr}_{3}$ & -1.59 & -7.13 & 12.05 & -0.50 & -4.64 \\
\hline $\mathrm{AlH}_{3}$ & -3.71 & -8.43 & 15.61 & -3.16 & -2.65 \\
\hline $\mathrm{AlF}_{3}$ & -6.50 & -11.01 & 22.39 & -9.56 & -1.23 \\
\hline $\mathrm{AlCl}_{3}$ & -7.25 & -16.51 & 31.29 & -7.23 & -4.49 \\
\hline $\mathrm{AlBr}_{3}$ & -7.10 & -17.43 & 32.41 & -6.03 & -5.25 \\
\hline $\mathrm{GaH}_{3}$ & -4.00 & -9.56 & 17.88 & -2.76 & -2.82 \\
\hline $\mathrm{GaF}_{3}$ & -7.64 & -13.67 & 28.01 & -9.04 & -0.85 \\
\hline $\mathrm{GaCl}_{3}$ & -6.20 & -14.79 & 28.00 & -5.18 & -4.18 \\
\hline $\mathrm{GaBr}_{3}$ & -5.30 & -14.16 & 26.02 & -3.76 & -4.93 \\
\hline \multicolumn{6}{|l|}{$\mathrm{C}_{\mathrm{sp} 2}-\mathrm{F}$} \\
\hline $\mathrm{BH}_{3}$ & -9.66 & -18.55 & 33.79 & -5.36 & -4.47 \\
\hline $\mathrm{BF}_{3}$ & -5.69 & -6.46 & 11.92 & -1.75 & -1.35 \\
\hline $\mathrm{BCl}_{3}$ & -3.48 & -8.23 & 14.00 & -0.97 & -4.12 \\
\hline $\mathrm{BBr}_{3}$ & -3.87 & -10.20 & 17.52 & -1.23 & -4.70 \\
\hline $\mathrm{AlH}_{3}$ & -20.93 & -25.71 & 49.58 & -11.68 & -2.59 \\
\hline $\mathrm{AlF}_{3}$ & -29.66 & -23.14 & 48.64 & -19.29 & 1.47 \\
\hline $\mathrm{AlCl}_{3}$ & -32.03 & -38.52 & 75.92 & -22.05 & -2.87 \\
\hline $\mathrm{AlBr}_{3}$ & -33.82 & -44.06 & 86.41 & -22.76 & -3.48 \\
\hline $\mathrm{GaH}_{3}$ & -17.82 & -24.76 & 47.44 & -8.15 & -2.94 \\
\hline $\mathrm{GaF}_{3}$ & -30.27 & -27.60 & 57.46 & -17.12 & 1.70 \\
\hline $\mathrm{GaCl}_{3}$ & -27.10 & -35.34 & 69.65 & -15.63 & -3.02 \\
\hline $\mathrm{GaBr}_{3}$ & -26.93 & -38.99 & 75.62 & -15.29 & -4.18 \\
\hline \multicolumn{6}{|l|}{$\mathrm{C}_{\mathrm{sp} 3}-\mathrm{F}$} \\
\hline $\mathrm{BH}_{3}$ & -23.89 & -42.50 & 79.87 & -16.53 & -6.98 \\
\hline $\mathrm{BF}_{3}$ & -10.81 & -12.33 & 23.03 & -3.81 & -1.82 \\
\hline $\mathrm{BCl}_{3}$ & -5.77 & -11.42 & 19.65 & -1.78 & -4.43 \\
\hline $\mathrm{BBr}_{3}$ & -6.38 & -15.12 & 25.84 & -2.11 & -5.58 \\
\hline $\mathrm{AlH}_{3}$ & -30.61 & -34.02 & 65.84 & -16.06 & -2.62 \\
\hline $\mathrm{AlF}_{3}$ & -40.73 & -28.17 & 59.69 & -23.25 & 1.91 \\
\hline $\mathrm{AlCl}_{3}$ & -44.51 & -46.03 & 91.64 & -27.17 & -1.97 \\
\hline $\mathrm{AlBr}_{3}$ & -47.03 & -54.39 & 106.81 & -28.94 & -2.92 \\
\hline $\mathrm{GaH}_{3}$ & -25.76 & -33.19 & 63.67 & -11.30 & -3.55 \\
\hline $\mathrm{GaF}_{3}$ & -41.16 & -33.92 & 71.08 & -20.85 & 1.80 \\
\hline $\mathrm{GaCl}_{3}$ & -38.94 & -45.16 & 89.28 & -20.56 & -2.81 \\
\hline $\mathrm{GaBr}_{3}$ & -39.26 & -50.77 & 98.71 & -20.87 & -4.03 \\
\hline
\end{tabular}

of 3-4. The trends are consistent: for both $\mathrm{Al}$ and $\mathrm{Ga}$, the binding energies diminish in order $\mathrm{R}=\mathrm{F}>\mathrm{Cl}>\mathrm{Br}>\mathrm{H}$, and $\mathrm{AlR}_{3}$ engages in stronger complexes than does $\mathrm{GaR}_{3}$. The $\mathrm{BR}_{3}$ complexes are most weakly bound of all with $\mathrm{R}=\mathrm{H}$ forming the strongest bond.

Along with the better energetics of the $\mathrm{sp}^{2}$ complexes are larger measures of charge transfer. As exhibited in Table II, the total intermolecular transfer $\mathrm{Q}$ varies from a low of $0.01 e$ to as much as $0.09 e$. These quantities represent a $70 \%-280 \%$ enhancement relative to the sp dimers. The magnifications are quite similar for the $\mathrm{E}^{(2)}$
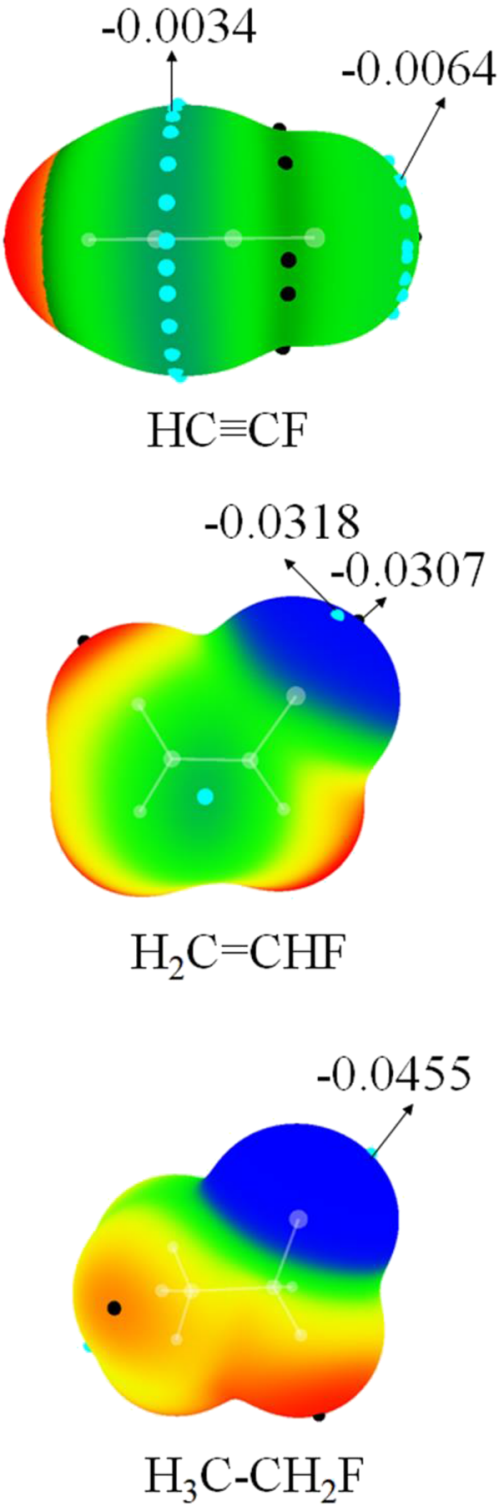

FIG. 2. MEP maps of $\mathrm{HC} \equiv \mathrm{CF}, \mathrm{H}_{2} \mathrm{C}=\mathrm{CHF}$, and $\mathrm{H}_{3} \mathrm{C}-\mathrm{CH}_{2} \mathrm{~F}$ on the $\rho=0.001$ a.u. isodensity surface. Color ranges, in a.u., are: red, greater than 0.02 ; yellow, between 0.02 and 0 ; green, between 0 and -0.02 ; and blue, smaller than -0.02 . Small blue and black spheres indicate the position of maxima and minima, respectively.

measure of inter-orbital transfer, which increases by $90 \%-360 \%$. The largest charge transfer parameters do not necessarily coincide with the strongest bond; for example, the $\mathrm{R}=\mathrm{Cl}$ and $\mathrm{Br}$ quantities exceed those for $\mathrm{R}=\mathrm{F}$. AIM measures of triel bond strength also are amplified by the conversion from $\mathrm{sp}$ to $\mathrm{sp}^{2}$. The bond critical point density, for example, grows by $40 \%-180 \%$; the growth of the Laplacian is even larger, as much as $400 \%$. The trends in these AIM parameters more closely adhere to energetics, being largest for $\mathrm{R}=\mathrm{F}$ (again with the exception of $\operatorname{Tr}=\mathrm{B}$ ). 
TABLE V. Values of $\mathrm{V}_{\mathrm{s}, \max }(\mathrm{au})$ for $\mathrm{TrR}_{3}$ monomers, along the $\mathrm{C}_{3}$ axis of each molecule.

\begin{tabular}{lcccc}
\hline \hline & $\operatorname{TrH}_{3}$ & $\operatorname{TrF}_{3}$ & $\operatorname{TrCl}_{3}$ & $\operatorname{TrBr}_{3}$ \\
\hline $\mathrm{B}$ & 0.0753 & 0.1123 & 0.0578 & 0.0489 \\
$\mathrm{Al}$ & 0.1395 & 0.2626 & 0.1462 & 0.1245 \\
$\mathrm{Ga}$ & 0.1150 & 0.2065 & 0.1315 & 0.1125 \\
\hline \hline
\end{tabular}

The various components of the interaction energies are generally magnified by the $\mathrm{sp} \rightarrow \mathrm{sp}^{2}$ transition. The electrostatic element, for example, is raised by between $140 \%$ and $630 \%$, making it clearly the largest contributor after exchange. A somewhat smaller rise in polarization energy places this component second to $\mathrm{E}^{\mathrm{ele}}$. The dispersion energy is affected to a much smaller degree, even becoming smaller in certain instances, such that it makes minimal contributions to these complexes.

A glance at Fig. 2(b) reveals an extensive blue region around the $\mathrm{F}$ atom of $\mathrm{H}_{2} \mathrm{C}=\mathrm{CHF}$, with a MEP minimum of -0.032 a.u. near the extension of the $\mathrm{C}-\mathrm{F}$ bond. This much more intense minimum correlates with the much larger electrostatic component in Table IV for the $\mathrm{sp}^{2}$ dimers. However, its placement along the bond axis does not explain the large deviations of $\alpha$ from $180^{\circ}$ in Table I. This displacement can be best understood by the presence of secondary interactions in these complexes. In addition to the primary $\mathrm{Tr} \cdots \mathrm{F}$ triel bond, the $\mathrm{H}$ the $=\mathrm{CHF}$ group is in position to form a $\mathrm{CH} \cdots \mathrm{R} \mathrm{H}$-bond to a halogen atom of $\operatorname{TrR}_{3}$. This $\mathrm{H}$-bond is facilitated by the proximate position of the $\mathrm{F}$, which pulls electron density and more strongly polarizes the $\mathrm{C}-\mathrm{H}$ bond. These secondary interactions, along with their attendant distances, are displayed in Fig. S1. A more complete listing of secondary interactions as identified by AIM is supplied in Table SI. The bond critical point densities are generally considerably smaller than the triel bond quantities but cannot be ignored. Taking $\mathrm{GaF}_{3}$ as an example, $\rho_{\mathrm{BCP}}$ for the triel bond is 0.0540 a.u., while the same quantity for the secondary bond is 0.0116 a.u. In any case, it is clear that the interaction energies in Table I cannot be attributed exclusively to the triel bond as there are supplements arising from the secondary interactions as well.

\section{$\mathrm{sp}^{3}$ alkanes}

Like the other systems, the complexes containing the $\mathrm{sp}^{3}$ hybridized $\mathrm{H}_{3} \mathrm{CCH}_{2} \mathrm{~F}$ also place the $\mathrm{Tr}$ atom significantly off the $\mathrm{C}-\mathrm{F}$ axis, with $\alpha$ angles in the last section of Table I that are within a few degrees of the $\mathrm{sp}^{2}$ quantities. The intermolecular $\mathrm{R}(\mathrm{Tr} \cdots \mathrm{F})$ distances, on the other hand, are very considerably shortened by the change to $\mathrm{sp}^{3}$ hybridization, shrinking by between $0.05 \AA$ and $0.27 \AA$. As one might expect, this bond contraction is accompanied by a very significant strengthening of the triel bond. The interaction energies grow larger by up to $8.7 \mathrm{kcal} / \mathrm{mol}$. This increase when compared to $\mathrm{sp}^{2}$ represents a rise by $35 \%-63 \%$ in most cases, with the exception of the more than doubling for $\mathrm{BH}_{3}$. The trends for the $\mathrm{sp}^{3}$ series essentially mimic those for the others: $\mathrm{R}=\mathrm{F}>\mathrm{Cl}>\mathrm{Br}>\mathrm{H}$ for $\mathrm{Tr}=\mathrm{Al}$ and $\mathrm{Ga}$, but when $\mathrm{Tr}=\mathrm{B}$, it is $\mathrm{BH}_{3}$ that is most strongly bound. Again one sees the trend that $\mathrm{Al}$ engages in the strongest triel bonds, followed by $\mathrm{Ga}$ and then $\mathrm{B}$.
Like the energetics, the total charge transfer Q on Table II is also magnified for the $\mathrm{sp}^{3}$ series when compared to $\mathrm{sp}^{2}$, increasing by $15 \%-26 \%$ for $\mathrm{Al}$ and $\mathrm{Ga}$, with larger percentage increases for $\mathrm{Tr}=\mathrm{B}$. The $\mathrm{E}^{(2)}$ quantities are also enhanced to the point that $\mathrm{NBO}$ views the triel bond in the complexes of $\mathrm{H}_{3} \mathrm{CCH}_{2} \mathrm{~F}$ with both $\mathrm{BH}_{3}$ and $\mathrm{AlCl}_{3}$ as covalent, so there is no $\mathrm{E}^{(2)}$ evaluated. The strength of this bond is further verified by the large AIM parameters in Table III for the $\mathrm{sp}^{3}$ complexes. Some of the bond critical point densities exceed 0.05 a.u., bordering on a covalent bond. This sort of designation is supported by the negative values of $\mathrm{H}$ for the strongest bonds, albeit even if only slightly negative.

The various components of the interaction energy in Table IV, with the exception of dispersion which is relatively static, all undergo an amplification upon $\mathrm{sp}^{3}$ hybridization of the $\mathrm{C}-\mathrm{F}$ bond. The electrostatic contribution, for example, rises by roughly $40 \%$ and by more than this for $\mathrm{Tr}=\mathrm{B}$. This increase is consistent with the larger value of $\mathrm{V}_{\mathrm{s} \text {, min }}$ on $\mathrm{H}_{3} \mathrm{C}-\mathrm{CH}_{2} \mathrm{~F}$, which is -0.046 a.u., as compared to -0.032 a.u. for $\mathrm{H}_{2} \mathrm{C}=\mathrm{CHF}$. The polarization energy also rises by some $20 \%-30 \%$ in most cases but again higher for $\operatorname{Tr}=\mathrm{B}$.

Like the previous case of $\mathrm{H}_{2} \mathrm{C}=\mathrm{CHF}, \mathrm{H}_{3} \mathrm{C}-\mathrm{CH}_{2} \mathrm{~F}$ also engages in secondary attractive interactions, mostly $\mathrm{CH} \cdots \mathrm{X} \mathrm{H}$-bonds. The most prominent of these are displayed in Fig. S2, which are largely responsible for the nonlinear $a(\mathrm{CF} \cdots \mathrm{Tr})$ angles. The last section of Table SI in the supplementary material reports the AIM quantities of those secondary interactions that result in a bond path. As in the $\mathrm{sp}^{2}$ cases, the triel bond parameters clearly exceed those of the secondary quantities, but note also that there can be more than one such secondary bond. $\mathrm{GaF}_{3}$, for example, has a triel bond critical point density with $\mathrm{H}_{3} \mathrm{CCH}_{2} \mathrm{~F}$ of 0.0631 a.u., which is complemented by three secondary bonds with densities of 0.0090 a.u., 0.0057 a.u., and 0.0051 a.u., respectively. So again, the interaction energies of many of the $\mathrm{sp}^{3}$ systems cannot be considered as the exclusive province of the triel bond.

\section{DISCUSSION}

As was noted above for each C-hybridization separately, the electrostatic and polarization energies roughly mirror the behavior of the total interaction energy. In fact, this approximation spans all three hybridizations. Figure 3(a) displays a rough linear relationship between $\mathrm{E}^{\text {int }}$ and $\mathrm{E}^{\text {ele }}$ for all systems combined, with the correlation coefficient $\mathrm{R}^{2}=0.92$. The correlation is slightly poorer for $\mathrm{E}^{\mathrm{pol}}$, with $\mathrm{R}^{2}=0.90$, as indicated in Fig. 3(b). The slope of 1.68 in Fig. 3(a) shows that the electrostatic energy rises more quickly than does the total interaction energy, while the slope is much closer to unity for the polarization energy in Fig. 3(b).

The engagement with the electron-donating molecule causes each $\mathrm{TrR}_{3}$ molecule to distort from its planar geometry into a trigonal pyramid shape. The energetic consequence of this deformation is encapsulated in the deformation energy (DE) quantities in Table I. DE correlates very roughly with the strength of the triel bond. For example, the $\mathrm{HC} \equiv \mathrm{CF}$ interaction energies do not exceed $5 \mathrm{kcal} / \mathrm{mol}$, and $\mathrm{DE}$ similarly peaks at $1 \mathrm{kcal} / \mathrm{mol}$. However, the interactions with $\mathrm{H}_{2} \mathrm{C}=\mathrm{CHF}$ which can exceed $20 \mathrm{kcal} / \mathrm{mol}$ correspond to deformation energies of almost $6 \mathrm{kcal} / \mathrm{mol}$. As the interaction energies rise further with $\mathrm{H}_{3} \mathrm{C}-\mathrm{CH}_{2} \mathrm{~F}$, up to $30 \mathrm{kcal} / \mathrm{mol}$, the $\mathrm{DE}$ climbs above $7 \mathrm{kcal} / \mathrm{mol}$. Furthermore, there is a clear correlation between 

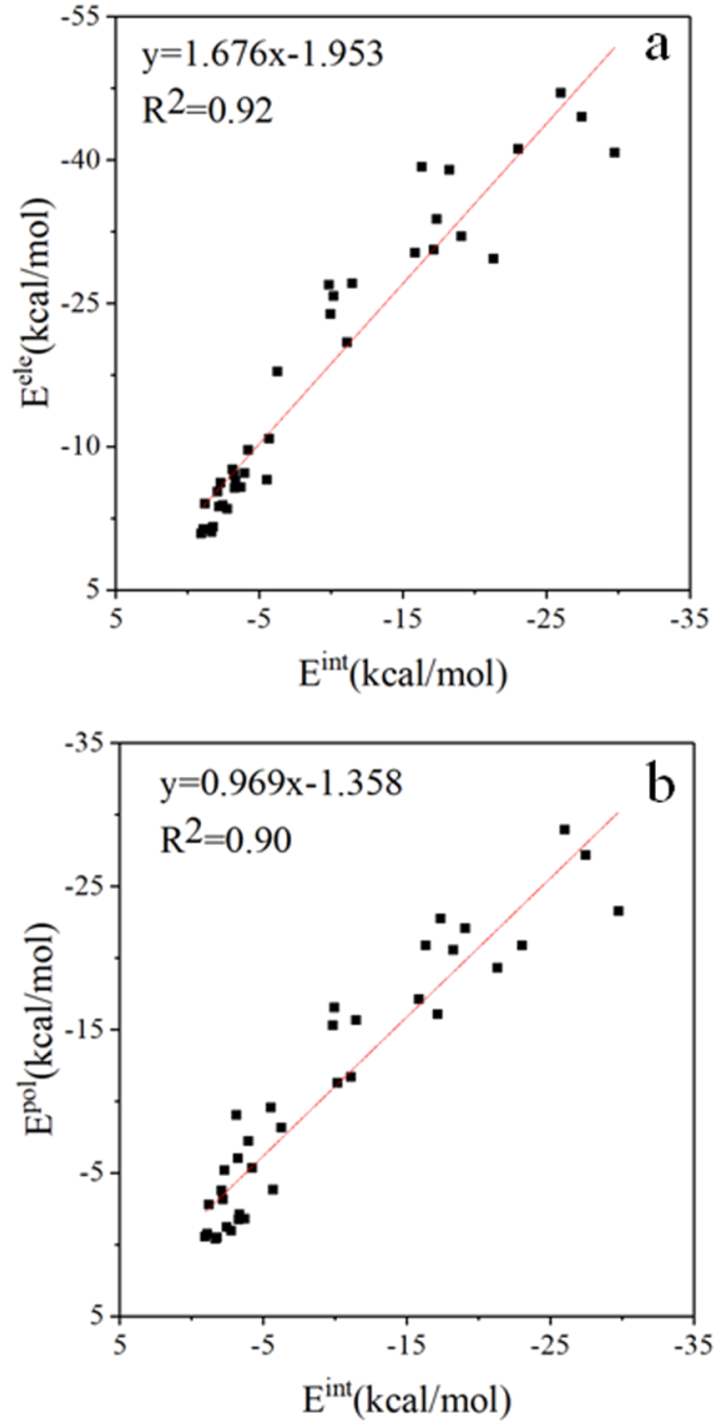

FIG. 3. Relationship between the interaction energy and (a) the electrostatic and (b) polarization energies.

the geometric distortion of $\operatorname{TrR}_{3}$ and the dissociation energy. Figure $\mathrm{S} 3$ documents a quadratic relationship between the mean angle of $\mathrm{R}-\operatorname{Tr} \cdots \mathrm{F}(\beta)$ and $\mathrm{DE}$ where $\beta=91+2.3 \mathrm{DE}+0.16(\mathrm{DE})^{2}$, a relationship which bears a correlation coefficient $R^{2}=0.97$.

The total amount of charge density transferred from the electron donor to the acceptor reaches its maximum of $0.118 e$ in $\mathrm{H}_{3} \mathrm{C}-\mathrm{CH}_{2} \mathrm{~F} \cdots \mathrm{BH}_{3}$, although CT is less than 0.1e for most of the complexes here. This quantity is much smaller than the charge transfer in triel bonds formed by carbene, $\mathrm{O} / \mathrm{N}$ electron donors (generally greater than $0.2 e$, even close to $0.8 e$ ). ${ }^{4}$

For both $\mathrm{sp}^{2}$ and $\mathrm{sp}^{3}$ hybridizations, QTAIM parameters suggest that $\mathrm{GaF}_{3}$ species participate in partly covalent interactions while $\mathrm{AlF}_{3}$ does not, even though the latter is the stronger Lewis acid. The Wiberg bond index (WBI) between the $\mathrm{Tr}$ and $\mathrm{F}$ atoms listed in Table $\mathrm{S} 2$ is larger in the $\mathrm{AlF}_{3}$ complexes than for $\mathrm{GaF}_{3}$, indi-

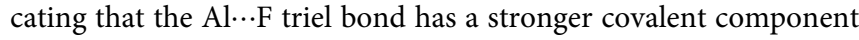
than does Ga $\cdots$ F. The energy density is sometimes a highly negative value for an ionic bond. ${ }^{57}$ One should thus be cautious in characterizing the covalent nature of a triel bond purely by means of QTAIM parameters.

There are some different trends for the B complexes and their $\mathrm{Al} / \mathrm{Ga}$ counterparts in Fig. 4. The $\mathrm{Al} \cdots \mathrm{F}$ and Ga...F triel-bonded complexes become more stable with the increase in $\mathrm{R}$ electronegativity. This is also true for the $\mathrm{B} \cdots \mathrm{F}$ triel-bonded complexes in both $\mathrm{sp}^{2}$ and $\mathrm{sp}^{3}$ hybridizations except that $\mathrm{R}=\mathrm{H}$ has the largest interaction energy. For sp hybridization, however, the B $\cdots$ F triel-bonded complexes have increasing interaction energy in the order $\mathrm{R}=\mathrm{F}$ $<\mathrm{H}<\mathrm{Cl}<\mathrm{Br}$, different than that in both $\mathrm{sp}^{2}$ and $\mathrm{sp}^{3}$ hybridizations. These trends are not completely consistent with the positive MEP on the $\pi$-hole of the triel atom. Both $\mathrm{E}^{\mathrm{int}}$ and $\mathrm{E}^{\mathrm{b}}$ are consistent with one another, so the inconsistency cannot be attributed to distortion of $\mathrm{TrR}_{3}$. Some inconsistent variations are also found between $\mathrm{E}^{\mathrm{int}}$ and the Wiberg bond index of $\operatorname{Tr} \cdots \mathrm{F}$ triel bond. Therefore, the different trends in Fig. 4 are possibly due to the secondary interactions even including repulsion interaction.

With regard to any possible relativistic effects arising for the larger atoms, interaction energies for systems containing $\mathrm{Br}$ and $\mathrm{Ga}$ were recalculated at the MP2/aug-cc-pVTZ(PP) level, which includes some account of relativistic effects. Their strong similarity with the aug-cc-pVTZ data indicates only very minimal relativistic effects.

The $\mathrm{F}$ atom has been considered as the nucleophilic source of electron density in triel bonds in the past, but the pertinent $\mathrm{F}$ was not bonded to $\mathrm{C}$ in an organic system. Nonetheless, these past studies can provide illuminating context for the results presented here. As one example, the $\mathrm{BH}_{2} \mathrm{X}(\mathrm{X}=\mathrm{F}, \mathrm{Cl}$, and $\mathrm{Br})$ dimer is held together by

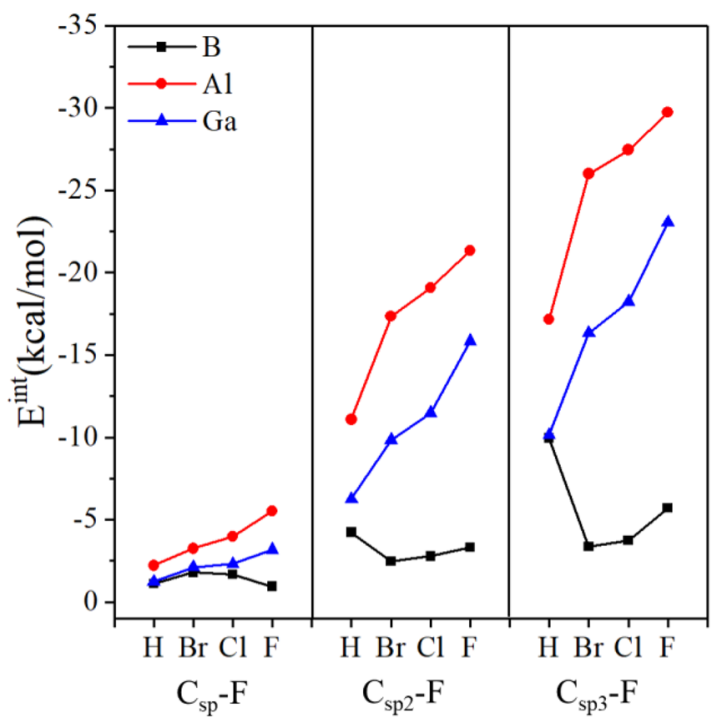

FIG. 4. Relationship between total interaction energies and nature of $T r$ and $R$ atoms in $\mathrm{TrR}_{3}$. 
a pair of triel bonds with $\mathrm{BX}$ as an electron donor. ${ }^{47}$ The interaction energy of the $\mathrm{BH}_{2} \mathrm{~F}$ homodimer is $-8.8 \mathrm{kcal} / \mathrm{mol}$ at the RI-MP2/augcc-pVQZ level, so each triel bond contributes $-4.4 \mathrm{kcal} / \mathrm{mol},{ }^{47} \mathrm{mak}-$ ing the $\mathrm{B}-\mathrm{F}$ bond a better electron donor than the $\mathrm{C}_{\mathrm{sp}}-\mathrm{F}$ bond, perhaps somewhere between the $\mathrm{C}_{\mathrm{sp} 2}-\mathrm{F}$ and $\mathrm{C}_{\mathrm{sp} 3}-\mathrm{F}$ bonds. Complexes between $\mathrm{BH}(\mathrm{CO})_{2} / \mathrm{BH}\left(\mathrm{N}_{2}\right)_{2}$ and $\mathrm{XF}_{3} / \mathrm{XF}_{5}(\mathrm{X}=\mathrm{Cl}, \mathrm{Br}$, and $\mathrm{I})$ are stabilized by both a halogen bond and a triel bond with $\mathrm{B} \cdots \mathrm{F}$ separation of $2.1 \AA-2.9 \AA{ }^{46}$ not unlike the $1.8 \AA-3.0 \AA$ range of the $\mathrm{BR}_{3} \ldots \mathrm{F}-\mathrm{C}$ systems considered here. Of course, replacing a neutral $\mathrm{R}-\mathrm{F}$ bond of any sort by a fluoride anion would raise the interaction energy.

As mentioned earlier, the $\mathrm{F}$ atom is not the most commonly studied electron donor in triel bonds, so it is of interest to compare it to others, e.g., $\mathrm{N}$ and $\mathrm{O}$. The $\mathrm{B} \cdots \mathrm{O}$ triel bond strength in $\mathrm{R}_{3} \mathrm{~B} \cdots \mathrm{OH}_{2}$ has little correlation with the particular substituent $\mathrm{R}$, while the $\mathrm{Al} / \mathrm{Ga} \cdots \mathrm{O}$ triel bond strength is clearly correlated with the R electronegativity, ${ }^{45}$ much like the trends in Table I. The weak $N$ electron donor $\mathrm{N}_{2}$ forms a $\mathrm{B} \cdots \mathrm{N}$ triel bond with interaction energy less than $-2 \mathrm{kcal} / \mathrm{mol},{ }^{58}$ similar to that seen here for the $\mathrm{C}_{\mathrm{sp}}-\mathrm{F}$ electron donor. In an interesting reversal, the triel bond involving $\mathrm{NCH}$ grows stronger in the order $\mathrm{BF}_{3}<\mathrm{BCl}_{3}<\mathrm{BBr}_{3}$, ${ }^{58}$ opposite to that for the $\mathrm{C}_{\mathrm{sp} 2}-\mathrm{F}$ and $\mathrm{C}_{\mathrm{sp} 3}-\mathrm{F}$ complexes described above. For an even stronger nucleophile such as $\mathrm{NH}_{3}$, the bond strength sequence becomes $\mathrm{BF}_{3}<\mathrm{BCl}_{3} \approx \mathrm{BBr}_{3}{ }^{58}$ It appears then that the dependence of triel bond strength on the B-substituent is a complicated one.

With regard to triel-bonding center, with $\mathrm{N}_{2}$ and $\mathrm{HCN}$ bases, ${ }^{59}$ the bond becomes stronger from $\mathrm{BR}_{3}$ to $\mathrm{GaR}_{3}$ to $\mathrm{AlR}_{3}$, consistent with the $\mathrm{C}-\mathrm{F}$ electron donor pattern seen here. For $\mathrm{NH}_{3}$, on the other hand, $\mathrm{BCl}_{3}$ forms a stronger triel bond than does $\mathrm{AlCl}_{3} .{ }^{59}$ The latter pattern persists for $\mathrm{N}$-heterocyclic carbene as an electron donor. ${ }^{42}$ This unusual result can be partly attributed to the facile distortion of $\mathrm{BR}_{3}$ caused by a strong electron donor.

Extending the scope beyond triel bonds, previous studies have shown that $\mathrm{C}-\mathrm{F}$ can serve as an electron donor in both $\mathrm{HBs}^{60}$ and XBs. ${ }^{61}$ However, these bonds are typically quite weak. For example, the $\mathrm{HB}$ interaction energy involving the $\mathrm{C}-\mathrm{F}$ electron donor seldom exceeds $-4 \mathrm{kcal} / \mathrm{mol} .{ }^{62}$ However, for the triel bond, the interaction energy is often larger than $-4 \mathrm{kcal} / \mathrm{mol}$ when the $\mathrm{C}_{\mathrm{sp} 2}-\mathrm{F}$ and $\mathrm{C}_{\mathrm{sp} 3}-\mathrm{F}$ act as an electron donor. That is, the $\mathrm{C}-\mathrm{F}$ bond appears to be a better electron donor in triel bonds than is the case in either HBs or XBs.

\section{CONCLUSIONS}

Organic fluorine connected with differently hybridized $\mathrm{C}$ atoms can serve in the capacity of an electron donor to form a triel bond with $\operatorname{TrR}_{3}$, and its strength is related to the hybridization of $C$, as well as the nature of both $\operatorname{Tr}$ and $\mathrm{R}$. These relationships are most plainly visible in Fig. 4. For any $\mathrm{C}$ hybridization, the $\mathrm{Al}$ complexes are more strongly bound than $\mathrm{Ga}$, which are, in turn, stronger than $\mathrm{B}$. For both $\mathrm{Al}$ and $\mathrm{Ga}$, the bond grows stronger in the order $\mathrm{R}=\mathrm{H}$ $<\mathrm{Br}<\mathrm{Cl}<\mathrm{F}$, i.e., with greater electronegativity. The same is true for $\operatorname{Tr}=\mathrm{B}$ except that $\mathrm{R}=\mathrm{H}$ forms a stronger bond than the others for both $\mathrm{sp}^{2}$ and $\mathrm{sp}^{3}$ hybridizations. Perhaps the most obvious trend in Fig. 4 is the progressive strengthening of the triel bond as one advances from $\mathrm{sp}$ to $\mathrm{sp}^{2}$ to $\mathrm{sp}^{3}$. Altogether, the triel bonds span a wide range of interaction energy, from only $1 \mathrm{kcal} / \mathrm{mol}$ for $\mathrm{Tr}=\mathrm{B}$ to as much as $30 \mathrm{kcal} / \mathrm{mol}$ for $\mathrm{H}_{2} \mathrm{C}=\mathrm{CHF} \cdots \mathrm{AlF}_{3}$.

NBO analysis shows that the principal orbital interaction of these triel bonds involves transfer from the lone pair of a Lewis base $\mathrm{F}$ to the empty $\mathrm{p}$ orbital of the $\mathrm{Tr}$ atom, regardless of the $\mathrm{C}$ hybridization. AIM confirms this triel bond as well as certain supplementary weaker $\mathrm{C}-\mathrm{H} \cdots \mathrm{X}$ H-bond and $\mathrm{F} \cdots \mathrm{C}$ interactions. The relative magnitudes of electrostatic, polarization, and dispersion energies are generally similar. Most of the complexes are dominated by electrostatics, but in some weak complexes, especially those involving $B$, the dispersion contribution is prominent.

The F-Tr dative bond has been found in several crystal structures, ${ }^{63,64}$ but no theoretical study has heretofore treated the C-F...Tr triel bond. This study will hopefully lead to a greater understanding of this type of triel bond with $\mathrm{C}-\mathrm{F}$ as electron donor.

\section{SUPPLEMENTARY MATERIAL}

See the supplementary material for Figs. S1-S3, Tables S1 and S2, and Cartesian coordinates.

\section{ACKNOWLEDGMENTS}

This work was supported by the National Natural Science Foundation of China (Grant No. 21573188).

\section{DATA AVAILABILITY}

The data that support the findings of this study are available within the article and its supplementary material.

\section{REFERENCES}

${ }^{1}$ A. Saha, S. A. Rather, D. Sharada, and B. K. Saha, Cryst. Growth Des. 18, 60846090 (2018).

${ }^{2}$ F. Zordan and L. Brammer, Cryst. Growth Des. 6, 1374-1379 (2006).

${ }^{3}$ D. E. Arkhipov, A. V. Lyubeshkin, A. D. Volodin, and A. A. Korlyukov, Crystals 9, 242 (2019).

${ }^{4}$ S. M. Walter, F. Kniep, E. Herdtweck, and S. M. Huber, Angew. Chem., Int. Ed. 50, 7187-7191 (2011)

${ }^{5}$ P. La Manna, M. De Rosa, C. Talotta, A. Rescifina, G. Floresta, A. Soriente, C. Gaeta, and P. Neri, Angew. Chem. 132, 821-828 (2020).

${ }^{6}$ S. Kuwano, T. Suzuki, M. Yamanaka, R. Tsutsumi, and T. Arai, Angew. Chem. 131, 10326-10330 (2019).

${ }^{7}$ M. G. Chudzinski, C. A. McClary, and M. S. Taylor, J. Am. Chem. Soc. 133, 10559-10567 (2011).

${ }^{8}$ J. Y. C. Lim, I. Marques, A. L. Thompson, K. E. Christensen, V. Félix, and P. D. Beer, J. Am. Chem. Soc. 139, 3122-3133 (2017).

${ }^{9}$ P. Molina, F. Zapata, and A. Caballero, Chem. Rev. 117, $9907-9972$ (2017).

${ }^{10}$ N. K. Shinada, A. G. de Brevern, and P. Schmidtke, J. Med. Chem. 62, 9341-9356 (2019).

${ }^{11}$ F.-Y. Lin and A. D. MacKerell, Jr., J. Phys. Chem. B 121, 6813-6821 (2017).

${ }^{12}$ Y. Lu, Y. Wang, Z. Xu, X. Yan, X. Luo, H. Jiang, and W. Zhu, J. Phys. Chem. B 113, 12615-12621 (2009).

${ }^{13}$ L. Brammer, E. A. Bruton, and P. Sherwood, Cryst. Growth Des. 1, 277-290 (2001).

${ }^{14}$ S. M. Malathy Sony and M. N. Ponnuswamy, Bull. Chem. Soc. Jpn. 79, 17661772 (2006).

${ }^{15}$ J. Nadas, S. Vukovic, and B. P. Hay, Comput. Theor. Chem. 988, 75-80 (2012). 
${ }^{16}$ B. K. Saha, A. Saha, D. Sharada, and S. A. Rather, Cryst. Growth Des. 18, 1-6 (2018).

${ }^{17}$ S. Dortéz, F. Fernández-Palacio, J. Damián, C. Gaiteiro, J. Ramos, P. Gómez-Sal, and M. E. G. Mosquera, CrystEngComm 22, 870-877 (2020).

${ }^{18}$ W. Sattler, S. Ruccolo, and G. Parkin, J. Am. Chem. Soc. 135, 18714-18717 (2013).

${ }^{19}$ W. A. Burns and K. R. Leopold, J. Am. Chem. Soc. 115, 11622-11623 (1993).

${ }^{20}$ D. L. Fiacco and K. R. Leopold, J. Phys. Chem. A 107, 2808-2814 (2003).

${ }^{21}$ D. L. Fiacco, Y. Mo, S. W. Hunt, M. E. Ott, A. Roberts, and K. R. Leopold, J. Phys. Chem. A 105, 484-493 (2001).

${ }^{22}$ J. Grotewold, E. A. Lissi, and A. E. Villa, J. Chem. Soc. A 1966, 1034-1037.

${ }^{23}$ J. Grotewold, E. A. Lissi, and A. E. Villa, J. Chem. Soc. A 1966, 1038-1041.

${ }^{24}$ H. Kameo, Y. Baba, S. Sakaki, Y. Tanaka, and H. Matsuzaka, Inorg. Chem. 59, 4282-4291 (2020).

${ }^{25}$ G. P. McGovern, D. Zhu, A. J. A. Aquino, D. Vidović, and M. Findlater, Inorg. Chem. 52, 13865-13868 (2013).

${ }^{26}$ E. C. Escudero-Adán, A. Bauzá, C. Lecomte, A. Frontera, and P. Ballester, Phys. Chem. Chem. Phys. 20, 24192-24200 (2018).

${ }^{27}$ S. J. Grabowski, ChemPhysChem 15, 2985-2993 (2014).

${ }^{28}$ S. J. Grabowski, ChemPhysChem 16, 1470-1479 (2015).

${ }^{29}$ Q. Tang and Q. Li, Mol. Phys. 113, 3809-3814 (2015).

${ }^{30}$ M. X. Liu, H. Y. Zhuo, Q. Z. Li, W. Z. Li, and J. B. Cheng, J. Mol. Model. 22, 10 (2016).

${ }^{31}$ Q.-Z. Li, L. Sun, X.-F. Liu, W.-Z. Li, J.-B. Cheng, and Y.-L. Zeng, ChemPhysChem 13, 3997-4002 (2012).

${ }^{32}$ M. Michalczyk, W. Zierkiewicz, and S. Scheiner, ChemPhysChem 19, 31223133 (2018).

${ }^{33}$ J. Zhang, Z. Wang, S. Liu, J. Cheng, W. Li, and Q. Li, Appl. Organomet. Chem. 33, e4806 (2019).

${ }^{34}$ S. J. Grabowski, Phys. Chem. Chem. Phys. 19, 29742-29759 (2017).

${ }^{35}$ S. Grabowski, Crystals 9, 503 (2019).

${ }^{36}$ S. Grabowski, Molecules 20, 11297-11316 (2015).

${ }^{37}$ S. J. Grabowski, Struct. Chem. 28, 1163-1171 (2017).

${ }^{38}$ A. Bauzá and A. Frontera, Theor. Chem. Acc. 136, 37 (2017).

${ }^{39}$ J. Zhang, Y. Wei, W. Li, J. Cheng, and Q. Li, Appl. Organomet. Chem. 32, e4367 (2018).

${ }^{40}$ M. Jabłoński, J. Comput. Chem. 39, 1177-1191 (2018).

${ }^{41}$ M. D. Esrafili and F. Mohammadian-Sabet, Struct. Chem. 27, 1157-1164 (2016).
${ }^{42}$ Z. Chi, W. Dong, Q. Li, X. Yang, S. Scheiner, and S. Liu, Int. J. Quantum Chem. 119, e25867 (2019).

${ }^{43}$ H. Ishikawa, A. Saito, M. Sugiyama, and N. Mikami, J. Chem. Phys. 123, 224309 (2005).

${ }^{44}$ S. J. Grabowski, Coord. Chem. Rev. 407, 213171 (2020).

${ }^{45}$ Z. Chi, Q. Li, and H. B. Li, Int. J. Quantum Chem. 120, e26046 (2020).

${ }^{46}$ W. Dong, Y. Wang, X. Yang, J. Cheng, and Q. Li, J. Mol. Graphics Modell. 84, 118-124 (2018).

${ }^{47}$ A. Bauzá and A. Frontera, ChemPhysChem 17, 3181-3186 (2016).

${ }^{48}$ R. Berger, G. Resnati, P. Metrangolo, E. Weber, and J. Hulliger, Chem. Soc. Rev. 40, 3496-3508 (2011).

49 J. D. Dunitz and R. Taylor, Chem. Eur. J. 3, 89-98 (1997).

${ }^{50}$ M. J. Frisch, G. W. Trucks, H. B. Schlegel et al., Gaussian 09, Revision A.02, Gaussian, Inc., Wallingford, 2009.

${ }^{51}$ S. F. Boys and F. Bernardi, Mol. Phys. 19, 553-566 (1970).

${ }^{52}$ F. A. Bulat, A. Toro-Labbé, T. Brinck, J. S. Murray, and P. Politzer, J. Mol. Model. 16, 1679-1691 (2010).

${ }^{53}$ R. F. W. Bader, AIM2000 Program, v.2.0 (McMaster University, Hamilton, Canada, 2000).

${ }^{54}$ A. E. Reed, L. A. Curtiss, and F. Weinhold, Chem. Rev. 88, 899-926 (1988).

${ }^{55}$ P. Su and H. Li, J. Chem. Phys. 131, 014102 (2009).

${ }^{56}$ M. W. Schmidt, K. K. Baldridge, J. A. Boatz, S. T. Elbert, M. S. Gordon, J. H. Jensen, S. Koseki, N. Matsunaga, K. A. Nguyen, S. Su, T. L. Windus, M. Dupuis, J. A. Montgomery, Jr., J. Comput. Chem. 14, 1347-1363 (1993).

${ }^{57}$ S. Pan, A. Gupta, S. Mandal, D. Moreno, G. Merino, and P. K. Chattaraj, Phys. Chem. Chem. Phys. 17, 972-982 (2015).

${ }^{58}$ S. J. Grabowski, J. Comput. Chem. 39, 472-480 (2018).

${ }^{59}$ S. J. Grabowski, Molecules 25, 2703 (2020).

${ }^{60}$ J. A. K. Howard, V. J. Hoy, D. O'Hagan, and G. T. Smith, Tetrahedron 52, 12613-12622 (1996).

${ }^{61}$ M. S. Pavan, K. D. Prasad, and T. N. G. Row, Chem. Commun. 49, 7558-7560 (2013).

${ }^{62}$ C. Dalvit, C. Invernizzi, and A. Vulpetti, Chem. Eur. J. 20, 11058-11068 (2014).

${ }^{63}$ Z.-G. Hu, M. Yoshimura, K. Muramatsu, Y. Mori, and T. Sasaki, Jpn. J. Appl. Phys., Part 2 41, L1131-L1133 (2002).

${ }^{64}$ R. K. Li and Q. D. Zeng, J. Cryst. Growth 382, 47-51 (2013). 